\title{
Event Study on the Reaction of Stock Returns to Acquisition News
}

\author{
Fotoh Lazarus Elad \\ Karlstad Business School, Karlstad University, Sweden \\ Tel: 46-703-552551Ｅ-mail: fotohae@yahoo.com
}

Nko Solange Bongbee

TD Bank, Mississauga, Canada

Tel: 1-647-719-0666 E-mail: solangebongbee@gmail.com

$\begin{array}{lrr}\text { Received: Dec. 6, } 2016 & \text { Accepted: Jan. 9, } 2017 \quad \text { Published: Jan. 16, } 2017 \\ \text { doi:10.5296/ifb.v4i1.10409 } & \text { URL: http://dx.doi.org/10.5296/ifb.v4i1.10409 }\end{array}$

\begin{abstract}
This study examines the reaction of stock returns to acquisition news. A data of 51 observations of acquiring companies with publicly traded shares on the London Stock Exchange (FTSE100) is used over a period, from July 2012 to May 2013 with an estimation period [-100, -10] and test period $[-5,+5]$. The market model is applied here in order to predict future stock returns and the use of the simple regression to get the parameters of the regression equation. With this a test statistics obtained on average, is significantly positive and greater than the critical value. Therefore, the event of acquisition does appear to be related significantly to the abnormal returns and the null hypothesis being rejected.
\end{abstract}

Keywords: Event study, Stock returns, Mergers and acquisition and abnormal return 


\section{Introduction}

A firm can grow its business either through internal expansion or external expansion. Internal expansion can include adopting new technology, business reengineering, new products and new marketing strategies. External expansion includes mergers and acquisitions (M\&A). It is the fastest growing option available for the firms and seen as an important exercise in corporate restructuring. Investors therefore use this opportunity to earn significant excess returns during an M\&A deal. The announcement of a Merger or an Acquisition is considered as an event in a study (Gopalaswamy et al., 2008). Event study methodology is used to find the effect of an event on a specific dependent variable. Here, the merger or acquisition announcement is an event and the underlying stock price is the dependent variable. The event study will investigate the change in stock price of the acquiring firms beyond expectation, which we call the "abnormal return" (Strong, 1992). The objective of this study is to investigate the effect of acquisition announcement on acquirer companies' stock prices over a period of time called an event window. Thus we look at the effect of the announcement few days before, during and after the event on share prices taking into consideration the daily closing prices of the stocks prior and post-acquisition announcement. The remainder of the paper is organized as follows; section 2 reviews the literature related to event studies, section 3 describes the data and the empirical methodology, section 4 presents and interprets results and section 5 presents the conclusion.

\section{Literature Review}

\subsection{Event Study}

An event study is a statistical method of an empirical investigation of the relationship between security prices and economic events (Dyckman et al., 1984). Most event studies have focused on the behavior of share prices in order to test whether their stochastic behavior is affected by the disclosure of firm-specific events. In a corporate context, the usefulness of event studies arises from the fact that the magnitude of abnormal performance at the time of an event provides a measure of the unanticipated impact of this type of event on the wealth of the firms' claimholders (Kothari \& Warner, 2006). Fama et al. (1969) presents useful evidence on how stock prices respond to information. Many studies focus on returns in a long run window while others focus on a short window that is, a few days around the event. A benefit of the short run approach centers around the fact that, with daily expected returns being close to zero, the model for expected returns tend not to have a big effect on inferences about abnormal returns.

\subsection{Efficient Markets}

As the world becomes increasingly globalized, firms are establishing strategic linkages alliances and M\&A in order to improve their ability to meet the many challenges they are constantly encountering in the course of doing business. The M\&A event is often surrounded by different theoretical aspects such as; the fact that an observation of the market reaction to news can be used to measure market efficiency and the news regarding M\&A signal value creation to the market. The Efficient Market Hypothesis (EMH) is based on the assumption 
that, in efficient markets, asset prices fully reflect all available information. Thus, any change in equilibrium prices will reflect the flow of information available to market participants (Simões et al., 2012). It therefore becomes impossible to make excess returns on this information. Malkiel (2003) points out that, no system could be devised to enable abnormal returns to be obtained if one accepts that market equilibrium conditions are translated into expected returns and that these are formed on the basis of the available information. There are equally situations whereby regularities detected in the market, would indicate inefficient information flow leading to a need to formulate a system to enable participants to obtain abnormal gains. According to Fama (1970), there exist three forms of market efficiency: weak form- trading on past trend; semi-strong form- trading on publicly available information and past trends; and strong form- trading on any information which may be public or private information (Roberts, 1967). Thus using the event study, statistical evidence are being derived from the fact that market prices do not immediately adjust to new information, and therefore tries to identify abnormal returns surrounding the M\&A.

\subsection{Mergers and Acquisition}

From the perspective of value creation, we observe that firms get into M\&A in order to share their capabilities with the main aim of improving their competitive advantages. According to Nohria \& Garcia-Pont (1991), sharing of capabilities tend to affect the parties' long-term competitiveness, therefore it requires some kind of long term commitment and interdependence on their part. Therefore the higher the level of interdependence, the greater the impact of the linkage upon the firms' performance in terms of their competitiveness, as such creating strategic value for the firms which will be reflected in their respective stock prices (Pfeffer \& Nowak, 1976). Thus fluctuation in the stock prices will lead to significant abnormal returns for the firms involved in the M\&A over a given period surrounding its announcement.

\subsection{Abnormal Returns (AR)}

There is a considerable variation in the measures of abnormal returns (AR) and the statistical test that empirical researchers used to detect abnormal stock returns (Barber \& Lyon, 1997). The works of Brown \& Waner $(1980,1985)$ and Campbell \& Wasley (1993), tend to focus on empirical specification and the power of test statistics in order to detect abnormal stock returns. These studies therefore focus on the features of AR measured on a particular day or at the most cumulated over several months. Similarly, our study looks at the empirical power and specification of test statistics of AR on daily basis of share prices cumulated over several days. Thus our work is based on short run event window of daily stock returns. In contrast to this, Barber \& Lyon (1997), and other researchers document the empirical power and specification of test statistics in order to detect long- run abnormal stock returns. This, unlike the short-run event studies, has no separate estimation period and of sample sizes which are usually in hundreds rather than tens of stock returns series.

\section{Hypothesis}

$\mathrm{H}_{0}$ : the event of acquisition does not have any relationship with the abnormal returns 
$\mathrm{H}_{1}$ : The event of acquisition does appear to be related significantly to the abnormal returns

Therefore, at this level, the specification on the direction of stock reaction to the announcement of the acquisition is expected to be stated after carrying out the test. Thus a two tailed test will be used in this case to determine the result of the event on stock reaction.

\section{Data and Empirical Methodology}

\subsection{Sample Selection and Data Description}

An event study typically tries to examine return behavior for a sample of firms experiencing a common type of event. In this case, initial sample consists of 51 acquisitions events over the period 03/01/2013 and 26/04/2013. Data of share prices for the estimation period and test period is obtained for the individual firms together with the Index (FTSE All Shares) from the Thomson Banker Mergers and Acquisitions Database (http://banker.thomsonib.com/ta). The acquirer firms are randomly picked U.K. firms with publicly traded shares on the London Stock Exchange (LSE). The estimation period runs from July 2012 to May 2013. We chose to carry out the study on the U.K firms because it has the most liquid and active takeover market after the U.S. and represents more than $65 \%$ of merger/acquisition transactions in Europe (Croci et al., 2010). Information patterning to target firms are excluded from the test, thus our focus is based on the acquirer firms.

\subsection{Identification of Time Parameters}

At this level we define what the test period, estimation period and event date (that is day zero) should be. The length of the event window (test period) is much shorter than that of the estimation period, with some variations with respect to the chosen intervals. An estimation period as suggested by Brown \& Warner (1985) is used to calculate a stock's Beta value. In this case we have an estimation period of 90 days [-100, -10] from which the alpha (intercept) and beta (slope coefficient) are derived by regressing the index's returns to the stock's returns. The beta is also a measure of the stock's volatility as compared with the market (Panayides \& Gong, 2002). According to Brown \& Warner (1985) a parameter estimation period of 120 days is adequate since daily returns data for the 120 days prior to the event date are sufficient in formulating a benchmark for normal returns. But this report considers an estimation period of 90 days and a test period of 10 days. An event window of 10 days fully captures the effects of the acquisition which we find of great interest in this report. The window begins from 5 days prior to the announcement date to 5 days after the event $[-5,+5]$ as seen on figure 1 below. Thus the test period is very small and gives us an impression of the immediate effect caused by the announcement of the acquisition around the event. 


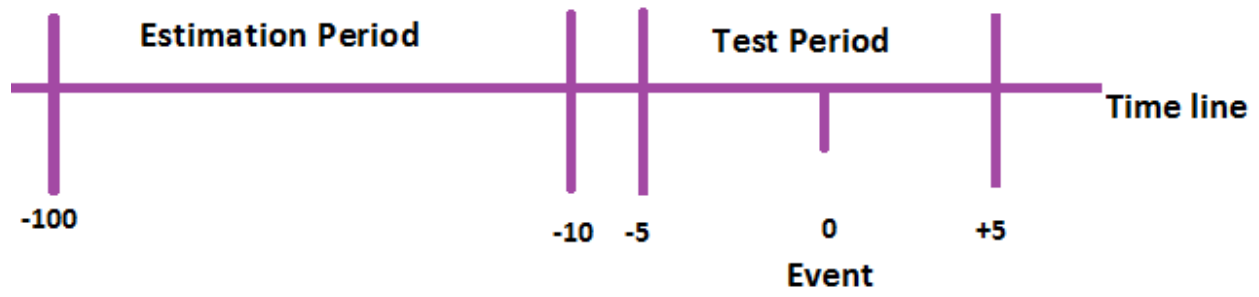

Figure 1. An illustration of the event study

Figure 1 above, illustrates the event study with the event window being $[-5,5]$ days and the estimation period is $[-100,-10]$ days and day zero [o] depicts the precise day of the event.

\subsection{Methodology Adopted}

The first step requires that datasets of share prices for the relevant dates, for each of the acquiring firms and the index to be studied were collected. In carrying out an event study, there is often a need for researchers to look at returns and not the direct share prices. Thus the share prices were transformed into natural logarithm returns and this was transformed using the formula below:

$$
R_{t}=L N\left(P_{t} / P_{t-1}\right)
$$

Where: $P$ is the observed price; Subscript $t$ refers to time $t ; \mathrm{P}_{\mathrm{t}}$ is the current price; and $\mathrm{P}_{\mathrm{t}-1}$ is the price of the previous trading day.

We try to figure out what the return would have been if the acquisition news hadn't been released. Thus the expected return is predicted by using a simple regression analysis, where the parameters are defined in the estimation period, consistent with an equilibrium model which is the market model procedure (MacKinlay, 1997) widely used as benchmark in event studies. A market model is a statistical model which relates stock returns to the return of the market portfolio which is the index. According to Strong (1992), the market model makes no explicit assumption about how equilibrium security prices are established and it instead assumes that returns are generated according to a given mechanism $\left[E\left(R_{i, t}\right)=\alpha_{i, t}+\beta_{i, j} R_{m t}\right]$. Therefore the simple regression is run using the returns on a given stock $i$ and the returns of a stock market index $m$. The market model is given as:

$$
E(R i, t)=\alpha i, t+\beta i, j R m t
$$

Where: $E\left(R_{i, t}\right)$ is the expected return at time $t, \alpha_{i}$ and $\beta_{i}$ are parameters of the regression equation. $\beta_{i}$ is the stock's Beta value (slope) and $R_{m t}$ is the daily return on a stock market index $m$ at time $t$.

In an event study, the measurement of abnormal return (AR) is often required to appraise the event's impact. Also, a benchmark for normal returns is required in order to test for the existence of AR which is defined as the difference between the actual observed return on the stock sample, $i$ and the predicted normal returns, $E\left(R_{i, t}\right)$, for each day of the event period (Seiler, 2003). Thus AR were calculated using the approach known as risk-adjusted return 
and measured over the event window on stock prices of selected firms which have undergone an M\&A deal. Therefore, the abnormal return of a stock $i$ at time $\mathrm{t}$ is given as equation (3).

$$
A R_{i, t}=R_{i, t}-E\left(R_{i, t}\right)
$$

Where: $\mathrm{AR}_{i, t}$ is the abnormal return; $\mathrm{R}_{i, t}$ is the actual return on stock, $i$; and $E\left(R_{i, t}\right)$ is the expected return.

Looking through most of the event studies carried out by researchers, abnormal returns are accumulated over a given number of periods. This is often done probably in order to accommodate uncertainty over the exact date of the event or to fully capture the effect of an event on share prices. The cumulative abnormal return (3) for security $i$ is computed as the sum of abnormal returns in a given time period $[\mathrm{t}, \mathrm{t}+\mathrm{k}]$ as shown in equation (4) below.

$$
C A R_{t, i t+k}^{i}=\sum_{k} A R_{i, t+k}
$$

Then, the CAR for each category that is, the average cumulative abnormal return of CAR across all the observations from event time $t$ to $\mathrm{t}+\mathrm{k}$ is given as;

$$
\overline{C A R}_{t, t+K}^{j}=\frac{1}{N_{j}} \sum_{n=1}^{N_{j}} C A R_{t, t+K}^{n}
$$

A test statistic is a measure of the likelihood that the actual value of the parameter is not zero. Thus it measures of some attribute of a sample by using the statistical hypothesis testing. The larger the absolute value of $t$, the less likely that the actual value of the parameter could be zero.

$$
t_{C A R}=\overline{C A R_{i \tau}} /\left(\sigma\left(C A R_{i \tau}\right) / \sqrt{n}\right)
$$

Where: $t_{C A R}$ is test statistic of cumulative abnormal return; $\overline{C A R_{i \tau}}$ is the CAR for each category; $\sigma$ is the standard deviation of the CAR of the various acquiring firms; and $n$ is number of observations.

\section{Presentation of Results}

Given the nature of an efficient market, it is impossible to make abnormal returns by trading on past trends, publicly available information or any other private information. Thus if there is no unusual movements in the stock returns around the event, then it's obvious that the average abnormal returns (AAR) will be fluctuating around zero which means the acquisition holds no information. But if the traders perceive the news just before the event and act upon it then there will be either a positive or negative movement in the daily AAR around the event. 


\section{Mll Macrothink}

Table 1. Average abnormal return and t-statistics within the event window

\begin{tabular}{|r|r|r|}
\hline Test period Average Abnormal Return t-Statistic \\
\hline-5 & -0.003491262 & -0.53491009 \\
\hline-4 & -0.001573894 & -0.24114255 \\
\hline-3 & $9.06672 \mathrm{E}-05$ & 0.01389148 \\
\hline-2 & 0.000159237 & 0.02439734 \\
\hline-1 & 0.001693853 & 0.25952197 \\
\hline 0 & 0.011146771 & 1.70784096 \\
\hline 1 & 0.016862927 & 2.58363587 \\
\hline 2 & 0.017715466 & 2.71425672 \\
\hline 3 & 0.016779815 & 2.57090187 \\
\hline 4 & 0.012935069 & 1.98183321 \\
\hline 5 & 0.018863967 & 2.89022308 \\
\hline
\end{tabular}

The table 1 above illustrates the AAR values and t-statistic over the test period $[-5,+5]$. The table shows that within the period before the acquisition news the AAR are negative for day -5 and day -4 and positive from day -3 to day -1 . Given the number of observations being 51 and a degree of freedom of 50, the critical value for the analysis turns out to be 2.009. With respect to this, the corresponding t-statistics results compared with the critical value show that at 5\% significance level, there is no significant value with the two-tailed test carried out for the pre-announcement days. Looking at the table from the event date, there has been a positive flow of AAR for all the days. When matched with the t-statistics, we see that almost all the days have significantly positive values except for the event day (day zero) itself and day +4 . However, on average the t-statistics (2.408) from the announcement day to day +5 shows a significant result being greater than the critical value. Therefore this means that there is a significant AR when the acquisition news is made and thus the null hypothesis should be rejected.

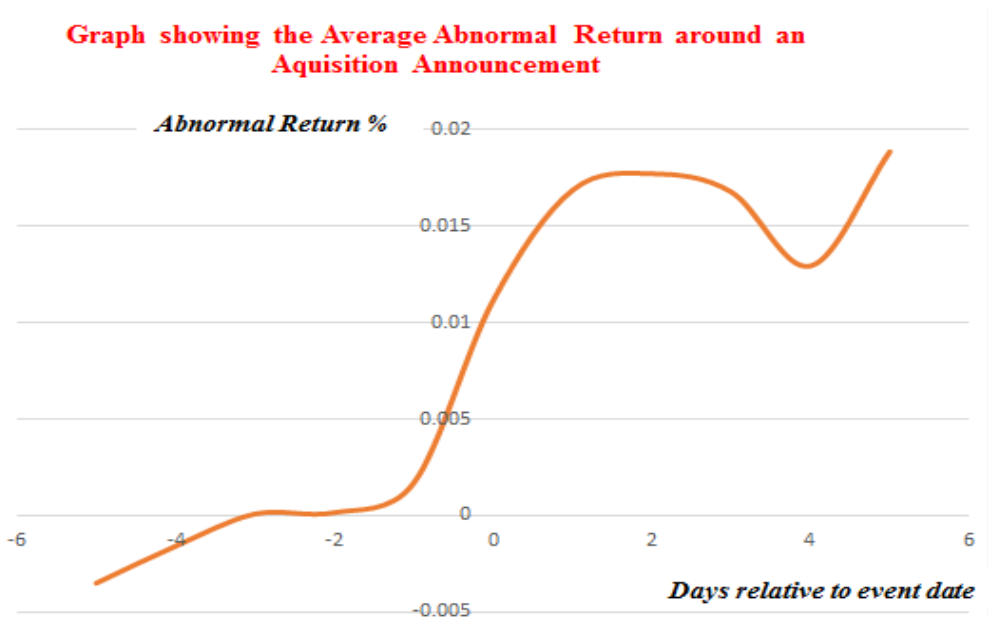

Figure2. An illustration average abnormal return around an acquisition event 
Figure 2 depicts the fluctuation in the average cumulative abnormal returns over the test period of -5 to +5 . As seen on the graph above, it shows an event of good news which began with a negative AAR on day -5 but move positively upward to the right to day +5 . The positive move in the event window began from day -3 as seen on the graph above. This shows possible leakage or anticipation of the news or it can equally be a sign of insider trading which gives some participants the opportunity to make excess returns. From day +1 $(1.69 \%)$, the returns jumped up sharply to day $+2(1.77 \%)$, then dropped down to day +4 . The sharp move in the returns shows that the market is efficient and respond to the news, thus having large impact on the AR. Though it started rising again on day $+5(1.89 \%)$, this may be due to some other industry specific news happening at the same time or suspicious reasons by the market participants.

\section{Conclusion}

This study investigates the effect of acquisition news on acquirer firms' stock return with the event being the acquisition announcement. A data (from July 2012 to May 2013) of daily returns for 51 observations of acquiring companies with publicly traded shares on the London Stock Exchange (LSE) is used for the analysis. The estimation period runs from -100 to -10 days while the test period is from -5 to +5 . The market model is applied here in order to predict future stock returns and the use of the simple regression to get the parameters of the regression equation. With this a test statistics obtained on average, is significantly positive and greater than the critical value (2.009) Therefore, the event of acquisition does appear to be related significantly to the abnormal returns and the null hypothesis being rejected.

What you see in share prices or stock returns, eventually gives an understanding of the attitude of market participants on their perceptions of what is happening in the market. A negative return will therefore imply that they have a negative feeling in the market while a positive return depicts that participants have positive feelings or are being bullish about market information. Using the market model for the analysis in this study, results of the test statistics show that they are bullish and therefore had positive feeling in the market about the acquisition news. Thus we reject the null hypothesis stated above and conclude that, event of acquisition is significantly related to abnormal returns.

\section{References}

Barber, B. M., \& Lyon, J. D. (1997). Detecting Long-run Abnormal Stock Returns: The Empirical Power and Specification of Test Statistics. Journal of Financial Economics, 43(3), 341-372. http://dx.doi.org/10.1016/S0304-405X(96)00890-2

Brown, S. J., \& Warner, J. B. (1980). Measuring Security Price Performance. Journal of Financial Economics, 8(3), 205-258. http://dx.doi.org/10.1016/0304-405X(80)90002-1

Brown, S. J., \& Warner, J. B. (1985). Using Daily Stock Returns: The Case of Event Studies. Journal of Financial Economics, 14(1), 3-31.

http://dx.doi.org/10.1016/0304-405X(85)90042-X

Campbell, C. J., \& Wesley, C. E. (1993). Measuring Security Price Performance using Daily 
NASDAQ Returns. Journal of Financial Economics, 33(1), 73-92.

http://dx.doi.org/10.1016/0304-405X(93)90025-7

Croci, E., Petmezas, D., \& Vagenas-Nanos, E. (2010). Managerial Overconfidence in High and Low Valuation Markets and Gains to Acquisitions. International Review of Financial Analysis, 19(5), 368-378. http://dx.doi.org/10.1016/j.irfa.2010.06.003

Dyckman, T., Philbrick, D., \& Stephan, J. (1984). A Comparison of Event Study Methodologies using Daily Stock Returns: A Simulation Approach. Journal of Accounting Research, 1-30. http://dx.doi.org/10.2307/2490855

Fama, E. F. (1970). Efficient Capital Markets: A Review of Theory and Empirical Work. The Journal of Finance, 25(2), 383-417.

Fama, E. F., Fisher, L., Jensen, M. C., \& Roll, R. (1969). The Adjustment of Stock Prices to New Information. International economic review, 10(1), 1-21.

http://dx.doi.org/10.2307/2525569

Gopalaswamy, A. K., Acharya, D., \& Malik, J. (2008). Stock Price Reaction to Merger Announcements: An Empirical note on Indian Markets. Investment Management and Financial Innovations, 5(1), 95-103.

Kothari, S. P., \& Warner, J. (2006). Econometrics of Event Studies. Handbook of Empirical Corporate Finance, 1, 3-36.

MacKinlay, A. C. (1997). Event Studies in Economics and Finance. Journal of Economic Literature, 13-39.

Malkiel, B. G. (2003). The Efficient Market Hypothesis and its Critics. Journal of economic perspectives, 17(1), 59-82.

Nohria, N., \& Garcia-Pont, C. (1991). Global Strategic Linkages and Industry Structure.

[Special Issue]. Strategic Management Journal, 12, 105-124.

http://dx.doi.org/10.1002/smj.4250120909

Panayides, M., \& Gong, X. (2002). The Stock Market Reaction to Merger and Acquisition Announcements in Liner Shipping. International Journal of Maritime Economics, 4. http://dx.doi.org/10.1057/palgrave.ijme.9100030

Pfeffer, J., \& Nowak, P. (1976). Joint Ventures and Interorganizational Interdependence. Administrative Science Quarterly, 21(3), 398-418. http://dx.doi.org/10.2307/2391851

Roberts, H. V. (1967). Statistical versus Clinical Prediction of the Stock Market. Unpublished manuscript, CRSP University of Chicago.

Seiler, M. J. (Ed.). (2003). Performing Financial Studies: A Methodological Cookbook. New Jersey: Pearson Prentice Hall.

Simões, M. D., Macedo-Soares, T. D. L., Klotzle, M. C., \& Pinto, A. C. F. (2012). Assessment of Market Efficiency in Argentina, Brazil and Chile: an Event Study of Mergers 
and Acquisitions. BAR-Brazilian Administration Review, 9(2), 229-245.

Strong, N. (1992). Modelling Abnormal Returns: A Review Article. Journal of Business

Finance \& Accounting, 19(4), 533-553.

http://dx.doi.org/10.1111/j.1468-5957.1992.tb00643.x

\section{Appendix}

Appendix 1. Cumulative abnormal stock returns for 51 acquiring companies

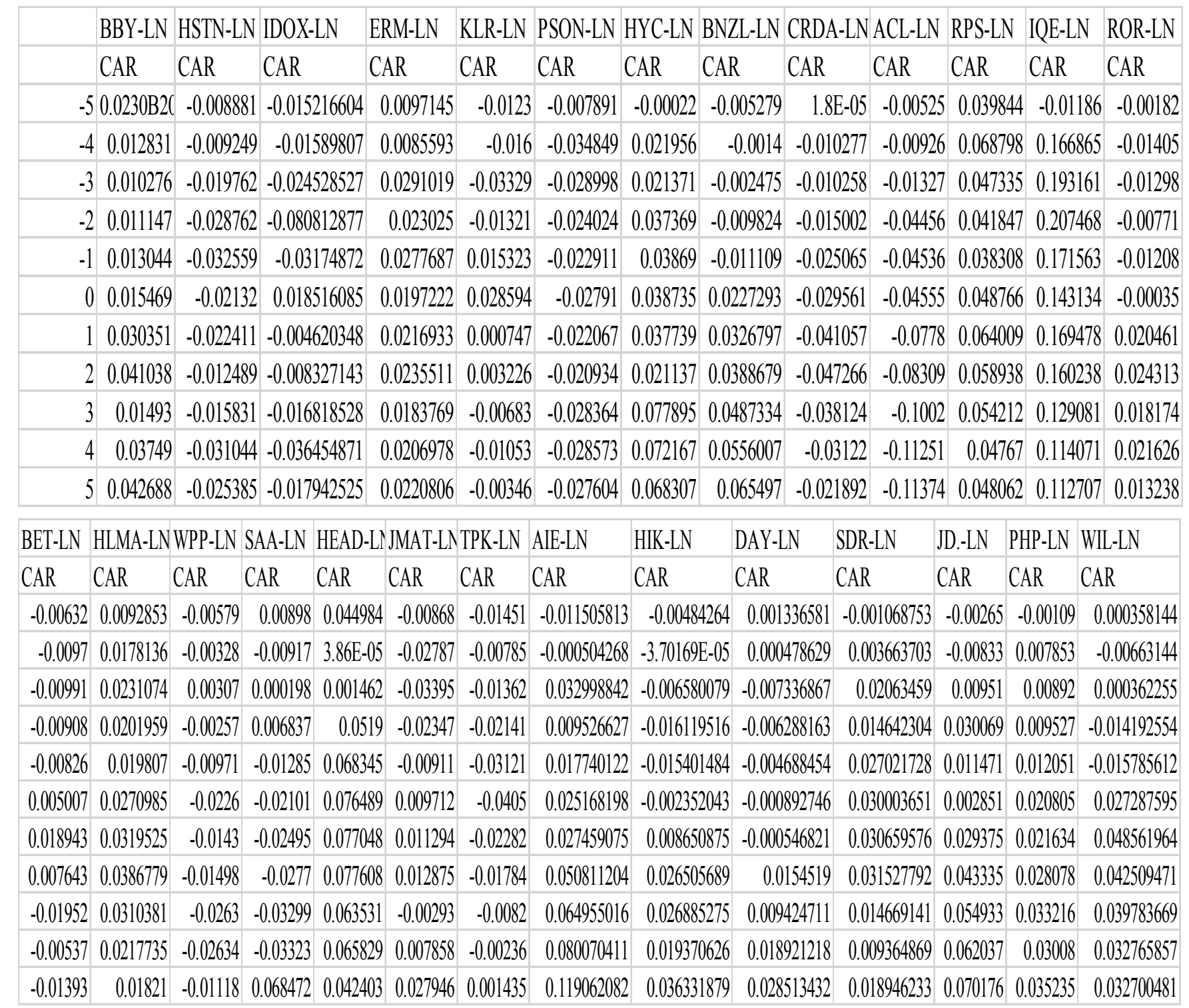




\begin{tabular}{|c|c|c|c|c|c|c|c|c|c|c|c|c|c|}
\hline 2D-LN & t & LN & LMP-I & TT.-LN & M & TEM-LN & PI-LN & $D C G$ & 1 & & & & \\
\hline$A R$ & CAR & -5 & CAR & CAR & CAD & & AR & CAR & $A R$ & R & & CAR & $A R$ \\
\hline 4 & t & 00033 & 5 & 70 & v & & $8 \quad-0$ & -0.0008 & 0.0 & & & 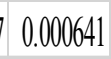 & \\
\hline 0.0072821 & -0.017 & & 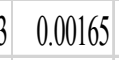 & $5-0$ & & & 0.0 & to & & & & 0 & 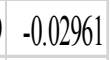 \\
\hline 0.0158596 & -0.012 & & 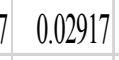 & 70007 & & & $\begin{array}{ll}4 & -0.0\end{array}$ & $00 ?$ & & & & -0.0 & 0.012 \\
\hline 0.0210106 & -0.006 & & 10.02 & 0.0 & & & $\begin{array}{ll}3 & -0.01554\end{array}$ & -0.030 & & & & -0.0 & -0.007 \\
\hline 20 & 0.0 & & 1 & 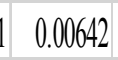 & & & $5-0.00295$ & -0.03029 & & & & & -0.016 \\
\hline 05764441 & -0.017 & & 0. & 0.1 & & & $5 \quad-0.1$ & -0. & & & & & -0.038 \\
\hline & -0.009 & & & $3-0$. & & & 0.0 & -0.0 & & & & & -0.031 \\
\hline & -0.004 & & & $8 \quad-0.0$ & & & & -0.03619 & & & & & .0022 \\
\hline & & & $8 \quad-0.0$ & $5 \quad-0.0$ & & & & -0.0 & & & & & 0088 \\
\hline & & & & $8-0$ & & & & & & & & 0.0200 & -0.044 \\
\hline 6648 & 0.004 & 94 & y & $y$. & 0.007498567 & & 40.042034 & & $-0.0+092$ & $0.00025 J$ & 782 & $2-0.04 J 11$ & $-0.024 J$ \\
\hline
\end{tabular}

\begin{tabular}{|c|c|c|c|c|c|c|c|c|c|}
\hline & & & & & & & & & \\
\hline $\mathrm{R}$ & CA & & & & & $\mathrm{D}$ & & & \\
\hline & & & & & & & & & \\
\hline & & & & & & & & & \\
\hline 0.02 & & & & & & & & & \\
\hline & & & & & & & & & \\
\hline & & & & & & & & & \\
\hline 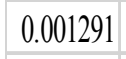 & 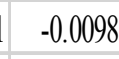 & & & & & & & & \\
\hline-0.004 & 600 & & 0.1 & & & & & & \\
\hline & & & & & & & & & \\
\hline & & & & & & & & & . \\
\hline & & & & & & & & & \\
\hline 0.01662 & -0.00 & 10 & 0.083 & 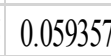 & -0.1 & 0.11068 & 0.0123 & .20448 & -0.04 \\
\hline
\end{tabular}

\section{Copyright Disclaimer}

Copyright for this article is retained by the author(s), with first publication rights granted to the journal.

This is an open-access article distributed under the terms and conditions of the Creative Commons Attribution license (http://creativecommons.org/licenses/by/3.0/). 